\title{
Cancer Cell Seeding Following Manipulation: An Ancient Concern According to the Traditional Iranian Medicine
}

\section{Letter to Editor}

\section{Dear Editor,}

Cancer diagnosis is a rapidly growing subject in both basic and clinical fields of research. New imaging systems, molecular diagnosis methods such as analysis of circulating markers $[1,2]$ as well as risk assessment approaches like genetic tests [3] are examples of advanced non-invasive diagnostic tools. Nevertheless, invasive methods remain to be more acceptable by physicians and even the patients $[4,5]$. Despite the great progression in noninvasive diagnostic methods, tissue biopsy is still the most reliable and accurate diagnostic tool when selection of right treatment strategy is concerned. There are three main biopsy methods:

1. Fine Needle Aspiration Biopsy (FNAB),

\section{Core Needle Biopsy (CNB) and}

\section{Surgical Biopsy.}

FNAB is performed by insertion of a needle (gauge 26-21) that is attached to a syringe pistol into the lesion and aspiration of sufficient amounts of cellular material. FNAB works better for loose tissues such as thyroid while is less effective in more dense tissues [6]. CNB is done with advantage of a thicker needle (up to $3 \mathrm{~mm}$ or more) which is inserted into the lesion with aid of local anesthesia. When arriving to the right place, the core needle is shot into the lesion and a cylindrical specimen is obtained [7]. This process might be done with or without assistance of imaging systems like ultra sound and MRI. Surgical (also open) biopsy is defined as partial (i.e. incisional) or complete (i.e. excisional) removal of the suspicious lesion. But the question raised here is that whether procedures utilized to obtain a biopsy specimen might hurt the patient? To address this question we first have to know the possible effects that a biopsy method might have on cancerous tissues. While in FNAB smallest damage is caused and in surgical excisional biopsy the whole lesion is removed, in CNB the thick needle is inserted into the lesion and might result into inflammatory response in tumor tissue. Virtually, this inflammatory reactions may facilitate other tissue injuries like tumor dis-integrity, vessel tearing, needle associated tissue movement, etc. [8]. The data on possible risks associated with needle biopsy are controversial. It is reported that macrophages repolarize from an M1 type toward tumor promoting M2 type after a tumor biopsy might accelerate tumor progression [9]. Several studies suggest that FNA can rarely cause needle track seeding or cutaneous metastasis at Biopsy Site in renal, pancreatic and hepatic (primary or metastatic) cancers [9-11]. As well, a few cases of breast cancer with the same complication after CNB have been reported $[12,13]$. There are also studies implying that procedures like prostate biopsy or surgical removal of the tumor during a colonoscopy (in colorectal cancer) may increase the number of circulating tumor cells (CTCs) in the blood in some

\author{
Letter to Editor \\ Volume 9 Issue 1 - 2017 \\ Sedigheh Asgary* \\ Cardiovascular Research Institute, Isfahan University of \\ medical Sciences, Iran \\ *Corresponding author: Sedigheh Asgary, Cardiovascular \\ Research Institute, Isfahan Cardiovascular Research Center, \\ Cardiovascular Research Institute, Isfahan University of \\ medical Sciences, Isfahan, Iran, Tel: 00989133094145; \\ Email: sasgary@yahoo.com
}

Received: April 11, 2017 | Published: October 10, 2017

cases $[14,15]$. Likewise, animal model studies in mice indicate that a biopsy of the breast tumor might increase the number of CTCs or risk of distant metastasis $[16,17]$. As well other manipulations such as pressure and laser treatment can increase the number of CTCs in nude mice with breast cancer $[18,19]$.

Collectively these data suggest that while distant or even needle track metastasis after different types of biopsy in human cancers is a very rare complication, mouse animal models of cancer show a much higher rate of metastasis after biopsy of the tumor.

These debates on getting biopsy from cancerous tissue, dates back to the ancient times. Avicenna (980-1037 A.D.), one of the most outstanding medical scientists ever [20], in his famous book, Cannon of medicine, insists that the cancerous tissue should not be manipulated. He recommends that during excisional surgery of the tumor, all affected tissue around the tumor should be excised completely and excessive bleeding should be allowed to clean the site from any suspicious cell [21]. Other Persian medicine pioneers like Seyed Esmail Jorjani (1042-1137 A.D.) and Hakeem Azam Khan (1211-1320 A.D.) also believe that the best cancer treatment methods are life style modification besides nutrition and drug prescription. They emphasize to care the cancerous tissue in a way it wouldn't be injured and avoid using blade unless necessary; as any manipulation is assumed to decrease the patient's life expectancy [22].

Eventually, although there is a very slight risk of distant metastasis following tumor biopsy, it is recommended to conduct larger studies on safety concerns arise from such methods.

\section{References}

1. Toriola AT, Laukkanen JA, Kurl S, Nyyssonen K, Ronkainen K, et al. (2013) Prediagnostic circulating markers of inflammation and risk of prostate cancer. Int J Cancer 133(12): 2961-2967. 
2. Murlidhar V, Ramnath N, Nagrath S, Reddy RM (2016) Optimizing the Detection of Circulating Markers to Aid in Early Lung Cancer Detection. Cancers 8(7).

3. Moyer VA (2014) Risk assessment, genetic counseling, and genetic testing for BRCA-related cancer in women: U.S. Preventive Services Task Force recommendation statement. Ann Intern Med 160(4) 271-281.

4. Collins GN, Lloyd SN, Hehir M, McKelvie GB (1993) Multiple Transrectal Ultrasound-Guided Prostatic Biopsies-True Morbidity and Patient Acceptance. Br J Urol 71(4): 460-463.

5. Aus G, Hermansson CG, Hugosson J, Pedersen KV (1993) Transrectal Ultrasound Examination of the Prostate: Complications and Acceptance by Patients. Br J Urol 71(4): 457-459.

6. Sidoti M, Marino G, Resmini E, Augeri C, Cappi C, et al. (2006) The rational use of fine needle aspiration biopsy (FNAB) in diagnosing thyroid nodules. Minerva Endocrinol 31(2): 159-172.

7. Pagni P, Spunticchia F, Barberi S, Caprio G, Paglicci C (2014) Use of Core Needle Biopsy rather than Fine-Needle Aspiration Cytology in the Diagnostic Approach of Breast Cancer. Case Rep Oncol 7(2): 452458

8. Bo Franzén RS, Hans Wiksell, Gert Auer (2016) Significance of Diagnostic Needle Biopsy for the Development of Inflammation, Tumour Progression and Metastasis. Journal of Molecular Biomarkers \& Diagnosis S2: 021.

9. Gibbons RP, Bush WH, Burnett LL (1977) Needle tract seeding following aspiration of renal cell carcinoma. J Urol 118(5): 865-867.

10. Tyagi R, Dey P (2014) Needle tract seeding: an avoidable complication. Diagn Cytopathol 42(7): 636-640.

11. Smith EH (1991) Complications of percutaneous abdominal fineneedle biopsy. Review. Radiology 178(1): 253-258.

12. Cho E, Kim MH, Cha SH, Cho SH, Oh SJ, et al. (2010) Breast Cancer Cutaneous Metastasis at Core Needle Biopsy Site. Ann Dermatol 22(2): 238-240.
13. Uematsu T, Kasami M (2008) Risk of needle tract seeding of breast cancer: cytological results derived from core wash material. Breast Cancer Res Treat 110(1): 51-55.

14. Koch M, Kienle P, Sauer P, Willeke F, Buhl K, et al. (2004) Hematogenous tumor cell dissemination during colonoscopy for colorectal cancer. Surg Endosc 18(4): 587-591.

15. Ladjevardi S, Auer G, Castro J, Ericsson C, Zetterberg A, et al. (2014) Prostate Biopsy Sampling Causes Hematogenous Dissemination of Epithelial Cellular Material. Dis Markers 2014: 6.

16. Hobson J, Gummadidala P, Silverstrim B, Grier D, Bunn J, et al. (2013) Acute inflammation induced by the biopsy of mouse mammary tumors promotes the development of metastasis. Breast Cancer Res Treat 139(2): 391-401.

17. Mathenge EG, Dean CA, Clements D, Vaghar-Kashani A, Photopoulos S, et al. (2014) Core Needle Biopsy of Breast Cancer Tumors Increases Distant Metastases in a Mouse Model. Neoplasia 16(11): 950-960.

18. Juratli MA, Sarimollaoglu M, Siegel ER, Nedosekin DA, Galanzha EI, et al. (2014) Real-time monitoring of circulating tumor cell release during tumor manipulation using in vivo photoacoustic and fluorescent flow cytometry. Head Neck 36(8): 1207-1215.

19. Weber M, Moebius P, Buttner-Herold M, Amann K, Preidl R, et al (2015) Macrophage polarisation changes within the time between diagnostic biopsy and tumour resection in oral squamous cell carcinomas--an immunohistochemical study. Br J Cancer 113(3) 510-519.

20. Zargaran A, Mehdizadeh A, Zarshenas MM, Mohagheghzadeh A (2012) Avicenna (980-1037 AD). J Neurol 259(2): 389-390.

21. Sina I (1997) The canon of medicine. Sharafkandi A, Tehran, Iran, pp. 190-193.

22. Azam Kan M (2011) 1387. Exir-e-Azam (The great Elexir). Almaee press (In Persian), Tehran, Iran, pp. 1322-1338. 